\title{
Human Amnion-derived Pluripotent Stem Cells as a Promising Source for Regenerative Medicine and Tissue Engineering
}

Shigeo Saito ${ }^{1-3,7 *}$, Shin-Wei Wang ${ }^{3-6}$, Chia-Chen Ku ${ }^{1-3}$, Chen-Lung Steve Lin ${ }^{2,3,5,6}$, Deng-Chyang Wu ${ }^{3-6}$, Yoshinobu Murayama and Kazunari K. Yokoyama ${ }^{1-3}$

${ }^{1}$ Division of Stem Cell Research

${ }^{2}$ Graduate Institute of Medicine

${ }^{3}$ Kaohshiung Medical University, 100 Shih-Chun 1st Road, San- Ming District 807 Kaohsiung, Taiwan, ROC

${ }^{4}$ Department of Gastroenterology

${ }^{5}$ Cancer Center

${ }^{6}$ Kaohsiung Medical University Hospital

${ }^{7}$ Saito Laboratory of Cell Technology, Yaita, Tochigi 329-1571, Japan

${ }^{8}$ College of Engineering, Nihon University, Koriyama, Fukushima 963-8642, Japan

\begin{abstract}
Stem cells are undifferentiated cells that can renew themselves and generate specialized cell types with specific functions in the body. Patient- specific pluripotent stem cells might offer a limitless source for transplantable cells and tissues to treat sufferer without causing immune-rejection. Current reprogramming methods to generate pluripotent stem cells involve viral transduction or plasmid transfection that rely upon transient expression of the reprogramming factors without integration of ectopic DNA into the genome. However, the generation of stem cells with high efficiency and safety should be needed for the clinical use.

We established human amnion-derived pluripotent cells (HAPCs) and HAPCs derived induced pluripotent stem cells. These cells expressed phenotypic marker characteristics of stem cells. Furthermore, HAPCs contributed to the formation of chimeric embryoid bodies and formed teratomas after injection to immno-deficient mice. We discuss here the possible application of human genetically unmodified pluripotent stem cells as well as induced pluripotent stem cells for regenerative medicine. Those stem cells that can be maintained by signaling through LIF/Stat3 may be required.
\end{abstract}

Keywords: Amnion; Pluripotent stem cells; ES cells; iPS cells; Reprogramming

\section{Introduction}

Human amnion derived cells are unique source for the generation of pluripotent stem cells which have vast therapeutic implications. These cells can be readily derived from placental tissue after delivery. The amnion is derived from the epiblast as early as 8 days after fertilization [1] and forms a thin membrane-lined cavity filled with fluid to protect the fetus. Epiblast forms the amnion as well as all of germ layers of the embryo. Thus, it is rational to consider that amnion might have the pluripotency of epiblast cells.

Stem cells are undifferentiated cells that can renew themselves and generate also one or more specialized cell types with specific functions in the body. Stem cells exist not only in embryo during development, but they also occur in adult tissues. Adult muscle stem cells rebuild a muscle and hematopoietic stem cells can restore all the different cell types found in blood. However, the potential of stem cells does not seem to be restricted by their source [2,3]. Multipotent adult progenitor cells from human, mouse, and rat bone marrow could produce almost every tissue types in the body, from blood to muscle, lung, brain and liver $[4,5]$. Thus, the potential use of stem cells seems quite huge and range from generating new neurons for treating with Parkinson's patients and to transplanting new cells that secrete insulin into pancreas with patients of diabetes.

Apart from adult somatic stem cells, pluripotent embryonic stem cells (ESCs) can make all somatic cell types of the mouse, including the germ line, when transferred to the blastocyst $(6,7)$. Since mouse ESCs were established, monkey [8], human [9] and rat [10,11] ESCs have been established to date. Another pluripotent stem cell lines with properties similar to mouse ESCs have been derived from a variety of developmental stages and mammalian species [12-14]. Previous approaches to obtain pluripotency, such as somatic cell nuclear transfer (cloning) or fusion of somatic cells with embryonic stem cells always encounter with ethical and technical difficulties that interfere the application of those cells to basic research and clinical therapy [15]. Thus, the direct generation of pluripotent cells without using embryos has been considered a more suitable strategies that avoids ethical concerns. Adult somatic cells can be reprogrammed by several combinations of transcription factors of pluripotency [16-18].

Introduction of the ectopic transcription factors activates a set of endogenous genes normally expressed only in ESCs and repress the expression program of differentiated cells, resulting in ESCs-like morphology and functionality. These reprogrammed cells were named induced pluripotent stem cells (iPSCs). Current reprogramming methods involve expression of putative oncogenes by retroviral vectors, which may themselves cause cancer by integrating into the genome in a way that disrupts endogenous gene expression. A desired protocol is to reduce the number of pluripotency factors and to use the safety delivery systems that do not involve the integration process. Contrary

*Corresponding author: Dr. Shigeo Saito, Saito Laboratory of Cell Technology, Yaita, Tochigi 329-1571, Japan, Tel: 81-287-48-0219; Fax: 81-287-48-0219; E-mail: saict1@maple.ocn.ne.jp

Received November 11, 2011; Accepted December 01, 2011; Published December 09, 2011

Citation: Saito S, Wang SW, Ku CC, Lin CLS, Wu DC, et al. (2011) Human Amnion-derived Pluripotent Stem Cells as a Promising Source for Regenerative Medicine and Tissue Engineering. J Bioengineer \& Biomedical Sci S2:005. doi:10.4172/2155-9538.S2-005

Copyright: (c) 2011 Saito S, et al. This is an open-access article distributed under the terms of the Creative Commons Attribution License, which permits unrestricted use, distribution, and reproduction in any medium, provided the original author and source are credited. 
Citation: Saito S, Wang SW, Ku CC, Lin CLS, Wu DC, et al. (2011) Human Amnion-derived Pluripotent Stem Cells as a Promising Source for Regenerative Medicine and Tissue Engineering. J Bioengineer \& Biomedical Sci S2:005. doi:10.4172/2155-9538.S2-005

to the established retroviral reprogramming method, reprogramming strategies of adenoviral transduction [19] and plasmid transfection [20] rely on transient expression of the reprogramming factors without integration of ectopic DNA into the genome. Yu et al. [21] derived human iPSCs free of vector and transgene sequences. Moreover, two groups established protein-induced pluripotent stem cells from mouse and human somatic cells $[22,23]$. The generation of iPSCs with high efficiency and safety should be needed for the clinical use.

However, both methods might be optimized more simply from the view point of timing and efficiency. Because, repeated transfection over 7 days is necessary to get reprogrammed cells from mouse fibroblasts by the method of Okita et al. [20]. Although the derivation of iPSCs seems rather simple, reprogramming process is slow and inefficient caused by unknown events. Procedure using with electroporation for plasmid transfection is obviously easier to use adenoviral transfection method.

Contrary to the characteristics of ESCs, mouse epiblast stem cells(mEPiSCs) are unable to contribute to normal tissues in chimeras in spite of having pluripotency to form all three germ layers in vitro and give rise to teratomas [24,25].

Human amnion derived-cells are easily attainable because amnion is generally discarded when delivery and amnion-derived multipotential cells have already been applied for the use of therapeutic treatment [26-29]. Recently, amniotic fluid derived stem cell lines which express embryonic stem cell markers (Oct4, SSEA-4) have been shown to have the multipotency [30] and to possess the possibility of new source for stem cell research [31]. Furthermore, other stemness makers, such as Sox2, Klf4 and c-Myc as well as Oct4 were also expressed in human amniotic fluid-derived or amnion-derived cells [31-33]. These cells could be induced to differentiate into cell types representing all three germ layers. However, they did not form teratomas in vivo, as do pluripotent stem cells,which is not consistent with our findings [34]. More recently, two groups reported the generation of reprogrammed human amniotic-derived iPSCs by retroviral-mediated or lentivirusmediated delivery of 4 or 3 of transcription factors [32,33]. However, they still use virus-mediated procedure to generate the human amniotic- derived iPSCs.

Maintenance of pluripotent state of ESCs depends on key molecular signaling pathways. Leukemia inhibitory factor (LIF) was identified as an important mediator that supports maintenance of pluripotency of murine ESCs by signaling through the Stat 3 pathway $[35,36]$. It is suggested that the same pathways influence the generation and maintenance of both ESCs and iPSCs [37]. However, the growth of human ESCs and iPSCs depends on signaling by FGF2, their growth is independent of LIF/Stat3 activity [38]. It has been pointed out that these stem cells share multiple defining features with mouse EPiSCs rather than mouse ESCs. This fact suggests that the proper conditions have not been devised for isolating human pluripotent stem cells with features similar to mouse naïve ESCs $[37,39]$. Human amnioticderived iPSCs were also cultured in the medium supplemented with FGF2 instead of LIF as a growth factor.

Here, we summarize our methods to establish both human amnion- derived pluripotent cells (HAPCs) and one- factor mediated HAPCs-iPS cells and discuss the possible applications of those cells for regenerative medicine.

\section{Isolation and characterization of HAPCs}

Protocols for isolating HAPCs are described in the Table 1 compared with those of mouse ESCs. Establishment and maintenance of HAPCs is not laborious because feeder cells are not necessary for cultivation. The cells grew rapidly in a monolayer, whose morphology was round and epithelial-like in shape and possessed oval nuclei with large multiple nucleoli (Figure 1a). Cell doubling time was $18 \mathrm{hrs}$ and they appeared to have normal karyotype even at 20th passage (Figure 1b). Chromosomal aberrations caused by multiple passages were not observed. The cells expressed markers of pluripotency, which include Oct4 and Nanog (Figure $1 \mathrm{c}, \mathrm{d}$ and Table 2).

\section{Contribution of HAPCs to chimeric embryoid bodies in vitro}

The mixture of EGFP transfected HAPCs (100 single suspended cells) and mouse ddy ES cells (100 single suspended cells) were culture in 50-100 $\mu \mathrm{L}$ MEM $\alpha$ supplemented with $10 \%$ of FBS without LIF under hanging drop condition system for 2-3 days and then cultured in the same medium for further 10 days under stationary conditions [40] AS shown in Figure $2 \mathrm{a}-\mathrm{h}$, the chimeric embryoid bodies were obtained and composed of all germ layers. Embryoid bodies are the structure that resembles the portion of cylindrical embryos. They initially appear
Mouse ESCs

Isolation Microsurgery of inner cell mass

Passage

Feeder

Medium

\section{Culture} conditions Mouse embryonic fibroblasts DMEM+10\%FBS+antibiotics 10ng/mL LIF, BMP4
HAPCs

Mincing of amniotic membrane with $0.25 \%$ Trypsin EDTA after cutting them into small pieces1-2 $\mathrm{mm}$ in diameter Culture in $0.25 \%$ Trypsin-EDTA Culture in $0.25 \%$ Trypsin-EDTA No feeder cell required MEM $\alpha+10 \%$ FBS+antibiotics $+10 \mathrm{ng} / \mathrm{mL}$ hLIF $37.5^{\circ} \mathrm{C}, 5 \% \mathrm{CO}^{2}$ in air

table 1:Protocols for generating mouse ESC and human amnion-derived pluripotent cells (HAPC) 
Citation: Saito S, Wang SW, Ku CC, Lin CLS, Wu DC, et al. (2011) Human Amnion-derived Pluripotent Stem Cells as a Promising Source for Regenerative Medicine and Tissue Engineering. J Bioengineer \& Biomedical Sci S2:005. doi:10.4172/2155-9538.S2-005

\begin{tabular}{llllll}
\hline Cell line & Feeder & $\begin{array}{l}\text { Growth } \\
\text { factor }\end{array}$ & $\begin{array}{l}\text { In vitro } \\
\text { pluripotency }\end{array}$ & $\begin{array}{l}\text { Teratoma } \\
\text { formation }\end{array}$ & $\begin{array}{l}\text { Expression Reference } \\
\text { of Oct4 }\end{array}$ \\
\hline
\end{tabular}

\begin{tabular}{|c|c|c|c|c|c|c|}
\hline $\begin{array}{l}\text { Amniotic } \\
\text { fluid-derived cells }\end{array}$ & - & - & + & - & + & (30) \\
\hline $\begin{array}{l}\text { Amniotic } \\
\text {-derived cells } \\
\text { Amniotic }\end{array}$ & - & hLIF & + & + & + & (34) \\
\hline -derived iPS cells & + & FGF2 & + & + & + & $(32,33)$ \\
\hline
\end{tabular}

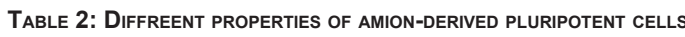

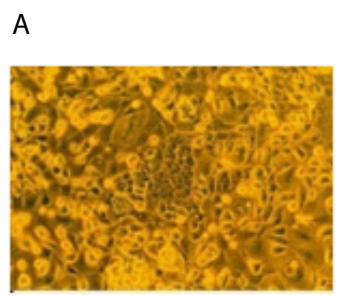

B
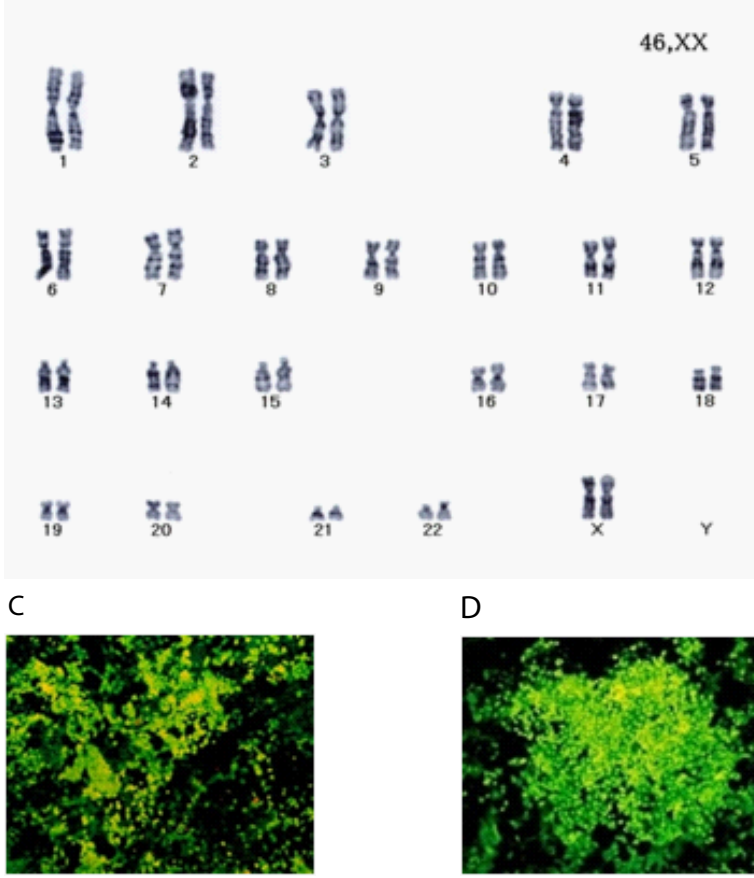

$\mathrm{D}$

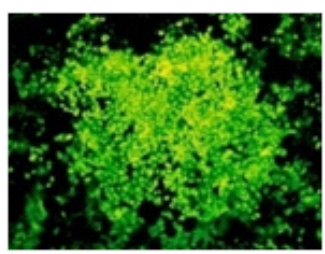

Figure 1: Phenotypic characterization of human amnion-derived pluripotent cells (HAPCs).

a) Morphology of HAPCs. These cells formed epiblast-like colony with spindle shaped cells that appeared under culture conditions at 20 days (passage 5) after the start of culture.

b) HAPCs-1 cells had a normal human karyotype and showed 46 and xx genotype of chromosome.

c), d) Pluripotency marker expression was confirmed by immunofluorescent staining of Oct4 (c) and Nanog (d). Magnification in a), c) and d) $\times 200$.

during embryogenesis-like development after 4 days of suspension culture from ES cells and have a hollow, spherical structure composed

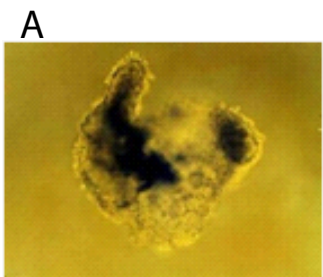

C
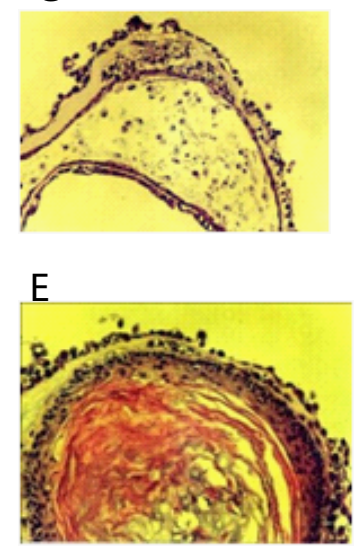

Figure 2: Differentiation ability of HAPCs in vitro. Contribution of HAPCs to chimeric embryoid bodies (EBs) composed of ddy mouse ESCs and EGFP transfected HAPCs were confirmed by histological preparation. a) Chimeric embryoid bodies (phase contrast) b) Large contribution of HAPCs was observed by fluorescent microscopy. c),d) Blood vessels and blood cells e),f) Skin and cartilage. Positive immuno-reactibility with antibody against EGFP was examined under fluorescent microscope. Magnification in $a, b) \times 200$ and in $c$ to f) $\times 400$.

of an outer layer of visceral endoderm and an inner layer of primitive ectoderm. Chimeric embryoid bodies showed that fluorescent HAPCs contributed to a large part of embryoid bodies and gave rise to cells of all germ layers in vitro (Figure $2 \mathrm{c}$-f ). Differentiated tissue included neural tube (ectoderm), blood islands, cartilage (mesoderm), liver and digestive tract (endoderm).

\section{Teratoma formation assay of HAPCs in vivo}

We tested the extent of differentiation of HAPCs by transplanting them subcutaneously into immuno-deficient nude mice of 6-weeks 
Citation: Saito S, Wang SW, Ku CC, Lin CLS, Wu DC, et al. (2011) Human Amnion-derived Pluripotent Stem Cells as a Promising Source for Regenerative Medicine and Tissue Engineering. J Bioengineer \& Biomedical Sci S2:005. doi:10.4172/2155-9538.S2-005

A
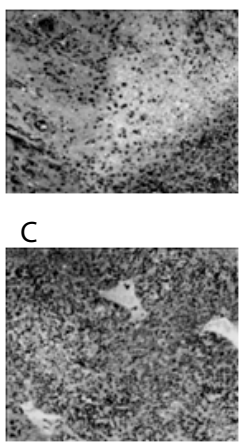

Figure 3: Differentiation ability of HAPCs in vivo. Teratomas formation by HAPCs in the subcutaneous tissue of immuno-deficient nude mice 2 months after of injection was examined. a) Immature neural tissue b) bone and c) immature liver were contained.
A

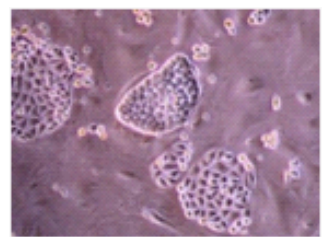

C

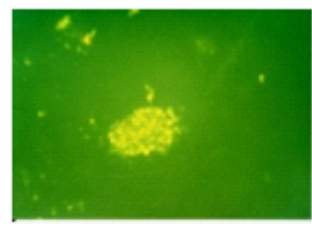

$\mathrm{E}$

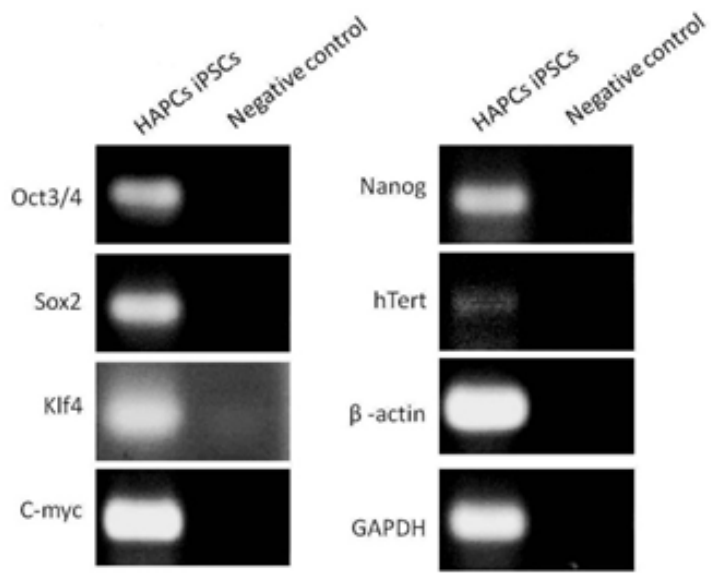

Figure 4: Phenotypic characterization of HAPCs- derived iPSCs. a) Morphology of HAPCs-iPSCs. Colonies depicted the compact colony structure resembled mouse ESCs on day 14 days after the treatment of electroporation. b) Alkaline phosphatase staining of HAPCs-iPSCs. c, d) Imunocytochemical analysis of pluripotency marker, Oct4 and Sox2. e) RT-PCR analysis of transcripts from pluripotency genes for Oct4, Sox2, KIf2, c-Myc, hTERT and Nanog in HAPCs-iPSCs. Magnification in a-d) $\times 200$.
A

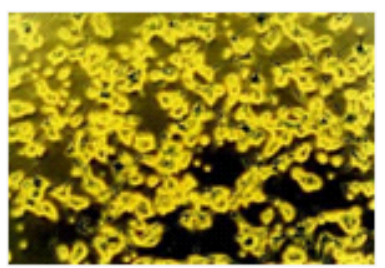

C

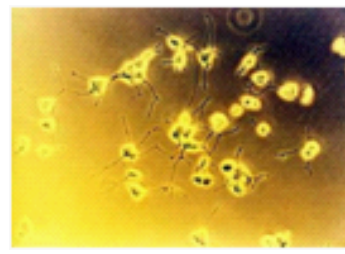

$\mathrm{E}$

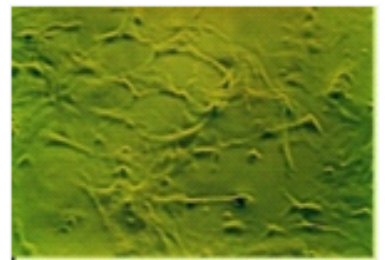

B

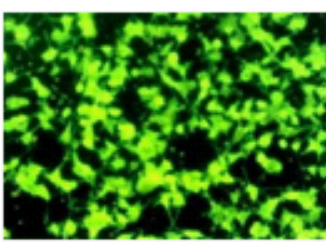

D

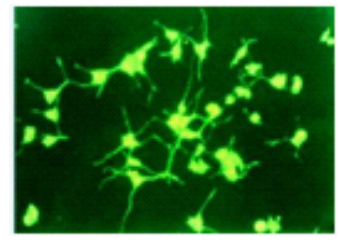

$\mathrm{F}$

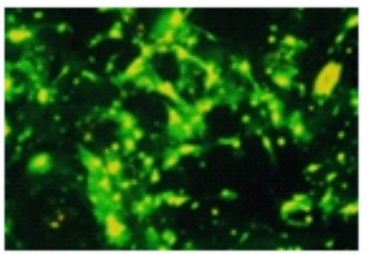

Figure 5: Differentiation ability of HAPCs-iPSCs in vitro. Cells were cultured in the medium supplemented with growth factors for inducing differentiation to neural cells and cardiomyocytes. a) Phase contrast image showing the extensive outgrowth of neural precursor structures from HAPCs-iPSCs. b) Immunostaining of the same culture as in a) with the neural precursor cells-specific antigen nestin. c) Phase contrast image showing the outgrowth of neuron. d) Immunostaining of the same culture as in c) with the neuron-specific antigen ß- tubulin. e ) Phase contrast image showing the development of cardiomyocyte precursors. f ) Immunostaining of the same culture as in e ) with the cardiomyocyte-specific antigen NKX 2.5. Magnification in a-f) $\times 200$.

old. For teratoma induction, $5 \times 10^{6}$ cells of HAP cells were collected. Teratomas were obtained by HAPCs in the subcutaneous tissue of mice ( 3 out of 8 ) at 2 months after injection and processed with hematoxylin and eosin staining. The resulting immature teratomas contained tissue representative of all germ layers, those were immature neural tissue(ectoderm), bone(mesoderm) and immature liver(endoderm) as shown in Figure 3 a-c.

\section{Generation of HAPCs-iPSCs via Sox 2 transcription factor by the use of electroporation}

Since several groups showed that human amnion derived cells expressed factors of pluripotency at levels lower than in iPS cells and values of relative expression of those factors in human amnion derived cells versus human iPSCs was the lowest in the case of Sox2, we decided to use Sox2 as a single factor to obtain reprogrammed HAPCs-iPSCs. Furthermore, the morphology of HAPCs is different from that of typical mouse ESCs. They form tight packed small colonies and can maintain this phenotype in the medium supplemented with LIF and BMP4. However, HAPCs do not form packed colony under the same culture conditions. Thus, more strong expression of the transcription factors of pluripotency might be necessary for HAPCs.

HAPCs were collected by trypsinization and $1 \times 10^{5}$ cells were utilized for transfection with reprogramming factor, Sox 2 by 
elctroporation (Day 0). Electric pulses (20V, 50 milli second apart, 10 times) were delivered to the $2 \mathrm{~mm}$ cuvettes containing $200 \mu \mathrm{l}$ of DMEM, $10 \mu \mathrm{g}$ of DNA and cells with an electoporator (CUY21 Vitro-EX, BEX Co., Ltd, Tokyo, Japan).The cells were cultured onto mitomycin C-treated mouse embryonic fibroblast (MEF) feeder layer using with DMEM medium supplemented with hLIF (5ng/mL; Sigma)

\section{Characterization of HAPCs-iPSCs}

HAPCs-iPS cell line maintained rather murine ES-like morphology and expressed strong expression of alkaline phosphatase activity (Figure $4 \mathrm{a}, \mathrm{b})$. We further tested the expression of the markers of pluripotency by immunofluorescent staining and RT-PCR assay after 20 passages. Oct4, SSEA-4 and Nanog were positive in the staining of each antibody and expression of Oct4, Sox2, Nanog, Klf4, c-Myc, hTERT and Nanog markers were confirmed by RT-PCR analysis (Figure $4 \mathrm{c}$-e). We discovered that the largest difference of phenotypic characteristics between HAPCs and HAPCs-iPSCs is the ability to form the small EScell like colonies.

\section{In vitro differentiation ability of HAPCs-iPSCs}

The ability to participate in the development of neural and cardiomyocyte cells was tested in vitro. Neural differentiation was accomplished for 14 days in the standard medium supplemented with FGF, EGF and PDGF (10 ng/mL), whereas cardiomyocyte differentiation was carried out for 10 days in standard medium supplemented with $1 \mathrm{mM}$ ascorbic acid 2-phosphate. Differentiation was detected by fluorescent immunostaining of outgrowth of cells (Nestin, GFAP and $\beta$-tubulin were for neural differentiation, Nkx 2.5 was for cardiomyocyte differentiation) (Figure $5 \mathrm{a}-\mathrm{f}$ ).

\section{Discussion}

Our human amnion- derived pluripotent cells (HAPCs) seem to have many features characteristics of pluripotent stem cells. 1) Those cells express pluripotency markers as Oct4 and Nanog. 2) The cells can be maintained for more than 30 passages under in vitro culture conditions and exhibits a normal human karyotype. Chromosome aberrations caused by passages are not observed. 3) Extended differentiation ability of cells to all three germ layers was confirmed by in vitro culture of mixture of embryoid bodies between HAP cells and ddy mouse ES cells. Chimeric embryoid bodies were composed of all germ layers that include epithelium (ectoderm), cartilage, blood islands (mesoderm) and digestive tract (endoderm). 4) Teratomas were obtained by HAP cells in the subcutaneous tissue of immuno-deficient mice after injection of cells. Teratomas contained all three kinds of germ layers. In addition, HAPCs have higher proliferation ability, which enable us to get substantial number of cells required for clinical transfer in a short time compared with bone-marrow derived mesenchymal stem cells that decrease in cell number, differentiation capability and proliferation ability with repeated passages [41-43]. Without signs of senescence or chromosomal aberration, passage- 20 cells can be used. Thus, we believe that these immortalized pluripotent cells have clinical relevance as a promising source of cells for regenerative therapy. Furthermore, because the use of oncogenes, retrovirus and other viruses in the current iPS cell generating protocol raises safety concerns. De Coppi et al. [30] reported isolation of human amniotic fluid-derived stem cells (AFSCs) that can be induced to differentiate to all cell types in three germ layers, but they cannot form teratomas in immuno-deficient mice after injection. This is not consistent with our results. HAPCs may represent a more pluripotential state and rapid conversion to a naïve ESCs-like state. However, the detailed molecular basis analysis of HAP cells might be needed to generate clinical quality of cells.

The molecular mechanisms and protein signal networks that mediate reprogramming are rather still elusive. Mouse embryos lacking either oct4 or Sox 2 do not form the epiblast that contains the population of pluripotent cells [44]. However, over- expression of either Oct 4 or Sox 2 brings them to the state of differentiation. The expression levels of Oct4 and Sox 2 must be important to maintain the state of pluripotency. The pluripotency circuit is known to act as a unit that strongly represses lineage specific gene expression in ESCs. Oct4 specifically represses only the neural ectodermal lineage, while Sox 2 specifically represses only the mesentodermal lineage. Together, Oct4 and Sox 2 repress differentiation into either germ layer lineage [45]. Thus, optimal expression levels of Oct 4 and Sox 2 is to be obtained to maintain the state of undifferentiated in pluripotent stem cells.

Zhao et al. [33] emphasized that human amnion -derived cells might be more easily reprogrammed than differentiated fibroblast cells because the ES-like colonies appeared on day 5-9 after the virus infected amnion -derived cells were replated into MEFs. In our case, ES-like colonies were detected on day 7 after the treatment of the delivery of Sox2 via electroporation to HAPCs. In contrast to amnion-derived cells, ES-like colonies are first observed in MEFs on day 10 -14 days. Therefore, it might be possible to consider that HAPCs might represent a more advanced stage in reprogramming process and subsequently these are reprogrammed earlier and more efficiently than differentiated cells. Pluripotent stem cells derived for therapeutic purposes will need the donor cells to be easily attainable, less likely to contain genetic aberrations, and easy to reprogram with transient affections [15]. However, it is no doubt that only a small fraction of cells (no more than $5 \%$ of the cells) can form an iPSC, the information obtained from molecular analysis is still dissatisfied. The establishment of further efficient reprogramming technology needs to be resolved.

Under primary culture conditions, untransformed cells stop growing after several weeks and undergo senescence, a phenomenon that is related to cellular aging. Senescence protects normal cells from abnormal growth signals and oncogenic transformation, and impairs their reprogramming into pluripotent stem cells by interrupting the events of cell cycle [46]. During reprogramming, differentiated cells not only become pluripotent, but they also become immortal. The same culture conditions used for the maintenance of ESCs are currently adopted in both mouse and human iPSCs derivation $[16-18,32,33,38,47]$. The state of undifferentiated mouse ESCs is dependent on the expression of transcription factor, Oct4, Sox 2 and Nanog, and by signaling through the growth factors LIF and BMP4 [35]. Two groups reported the derivation of iPS cell lines from human amnionotic -derived cells, were using culture conditions without LIF but including FGF2 [32,33]. A combination of FGF2 and activin signaling maintains self-renewal of human ESCs [48]. LIF signaling does not support self-renewal of both human ESCs and iPSCs. The growth factor conditions required for self-renewal of HAPCs is clearly different from those of other human pluripotent stem cells. Our results demonstrate that HAPCs and HAPCs-derived iPSCs are rather resemble the naïve pluripotent state of mouse ESCs $[37,49]$. As shown in Figure 1-5, LIF/Stat3 signaling seems sufficient to stabilize the pluripotent state of both HAPCs and HAPCs-iPSCs in the absence or presence of feeder cells. Interestingly, Reubinoff and co-workers reported the supplementation of LIF to the culture medium to generate 
Citation: Saito S, Wang SW, Ku CC, Lin CLS, Wu DC, et al. (2011) Human Amnion-derived Pluripotent Stem Cells as a Promising Source for Regenerative Medicine and Tissue Engineering. J Bioengineer \& Biomedical Sci S2:005. doi:10.4172/2155-9538.S2-005

Page 6 of 7

human ESCs [50]. Understanding the different pathways that can lead to reprogramming should help us to clarify the range of different state of pluripotency.

Tissue amnion seems to be an ethically non-controversial and reliable source of cells with stem cell-like properties. Here we show that human amnion-derived pluripotent cells (HAPCs) themselves are stem cells capable of generating multiple lineages including all three germ layers. HAPCs would have a significant impact on tissue engineering and regenerative medicine because they could be genetically unmodified stem cells. Preserved stem cells might provide promising sources to transfer them to immuno-compatible patients and for the use of autologous transplantation.

\section{Acknowledgments}

The authors gratefully acknowledge the help of Drs. I. Ishiwata and T. Tamagawa to carry out the recent studies of human pluripotent stem cells. We are also grateful to Dr. G.Nunez for pcDNA3-FLAG. This work was partially supported by grants from National Science Council in Taiwan to K.K.Y (100-2320-B-037-020)

\section{References}

1. Miki T, Lehmann T, Cai H, Stolz DB, Strom SC (2005) Stem cell characteristics of amniotic epithelial cells. Stem Cells 23: 1549-1559.

2. Bjorson CR, Rietze RL, Reynolds BA, Magli MC, Vescovi AL (1999) Turning brain into blood: a hematopoietic fate adopted by adult neural stem cell in vivo. Science 283: 534-537.

3. Jiang J, Chan YS, Loh YH, Cai J, Tong GQ et al. (2008) A core Klf circuitry regulates self-renewal of embryonic stem cells. Nat Cell Biol 10: 353-360.

4. Clarke DL, Clas BJ, Wilbertz J, Veress B, Nilsson E et al. (2000) Generalized potential of adult neural stem cells. Science 288: 1660-1663.

5. Woodbury D, Schwartz EJ, Prockop DJ, Black IB (2000) Adult rat and human bone marrow stromal cells differentiate into neurons. J Neuroscience Reserch 61: $364-370$

6. Evans MJ, Kaufman MH (1981) Establishment in culture of pluripotential cells from mouse embryos. Nature 292: 154-156.

7. Martin GR (1981) Isolation of a pluripotent cell line from early mouse embryos cultured in medium conditioned by teratocarcinoma stem cells. Proc Natl Acad Sci USA 78: 7634-7638.

8. Thomson JA, Kalishman J, Golos TG, During M, Hariss CP et al. (1995) Isolation of a primate embryonic stem cell line. Proc Natl Acad Sci USA 92 7844-7848.

9. Thomson JA, Itokovitz-Eldor J, Shapiro SS, Waknitz MA, Swiergiel JJ et al. (1998) Embryonic stem cell lines derived from human blastocysts. Science 282: $1145-1147$.

10. Buehr M, Meek S, Blair K, Yang J, Ure J et al. (2008) Capture of authentic embryonic stem cells from rat blastocysts. Cell 135: 1287-1298.

11. Li P, Tong C, Mehrian SR, Jia L, Wu N et al. (2008) Germline competent embryonic stem cells derived from rat blastcysts. Cell 135: 1299-1310.

12. MatsuiY, Zsebo K, Hogan BL (1992) Derivetion of pluripotential embryonic stem cells from murine primordial germ cells in culture. Cell 70: 841-847.

13. Kanatsu SM, Inoue K, Lee J, Yoshimoto M, Ogonuki N et al. (2004) Generation of pluripotent stem cells from neonatal mouse testis. Cell 119: 1001-1012.

14. Guan K, Nayenia K, Maier LS, Wagner S, Dressel R et al. (2006) Pluripotency of spermatogonia stem cells from adult mouse testis. Nature 440: 1199-1203.

15. Maherali N, Hochedlinger K (2008) Guidelines and techniques for the generation of induced pluripotent stem cells. Cell Stem Cell 3: 595-605.

16. Takahashi K, Yamanaka S (2006) Induction of pluripotent stem cells from mouse embryonic and adult fibroblast cultures by defined factors. Cell 126 $663-676$

17. Liao J, Cui C, Chen S, Ren J, Chen J, et al. (2009) Generation of induced pluripotent stem cell lines from adult rat cells. Cell Stem Cell 4: 11-15

18. Wu Y, Zhang Y, Mishra A, Tardif SD, Hornsby PJ, (2010) Generation of induced pluripotent stem cells from newborn marmoset skin fibroblasts. Stem Cell Res 4: 180-188.

19. Stadtfeld M, Hochedlinger K (2010) Induced pluripotency: history, mechanisms and applications. Genes Develop 24: 2239-2263.

20. Okita K, Nakagawa M, Hyenjong H, Ishikawa T, Yamanaka S (2008) Generation of mouse induced pluripotent stem cells without viral vectors. Science 332 949-953.

21. Yu J, Hu K, Smuga-Otto K, Tian S, Stewart R, et al. (2009) Human induced pluripotent stem cells free of vector and transgene sequences. Science 324 797-801.

22. Zhou H, Wu S, Joo JY, Zsu S, Han DW, et al. (2009) Generation of induced pluripotent stem cells using recombinant proteins. Cell Stem Cell 4: 381-384.

23. Kim D, Kim CH, Moon JI, Chung YG, Chang MY, et al. (2009) Generation of human induced pluripotent stem cells by direct delivery of reprogramming proteins. Cell Stem Cell 4: 472-476.

24. Brons IG, Smithers LE, Trotten MW, Rugg-Gunn P. Sun B, et al, (2007) Derivation of pluripotent epiblast stem cells from mammalian embryos. Nature 448: 191-195.

25. Tesar P, Chenoweth JG, Brook FA, Davies TJ, Evans EP, et al. (2007) New lines from mouse epiblast share defining features with human embryonic stem cells. Nature 448: 196-199.

26. Yeager AM, Singer HS, Buck JR, Matalon R, Brennan S, et al. (1985) A therapeutic trial of amniotic epithelial cell implantation in patients with lysosomal storage diseases. Am J Med Genet 22: 347-355

27. Scaggiante B, Pineschi A, Sustersich M, Andolina M, Agosti E, et al. (1987) Successful therapy of Niemann-Pick disease by implantation of human amniotic membrane. Transplantation 44: 59-61.

28. Sakuragawa N, Yoshikawa A, Sasaki M (1992) Amniotic tissue transplantation: clinical and biochemical evaluations for some lysosomal storage diseases, Brain Dev. 14: 7-11.

29. Sakuragawa N, Thangavel R, Mizuguchi M (1996) Expression markers for both neural and glial cells in human amniotic epithelial cells. Neurosci Lett 209: 9-12.

30. De Coppi P, Bartsch Jr G, Siddiqui MM, Xu T, Santos CC, et al. (2007) Isolation of amniotic stem cell lines with potential for therapy. Nat Biotechnol 25: 100106.

31. Prusa AR, Marton E, Rosner M, Bervaschek G, Hengstschlager M (2003) Oct4 expressing cells in human amniotic fluid: a new source for stem cell research? Human Reprod 18: 1489-1493.

32. Li C, Zhou J, Shi G, Ma Y, Yang Y, et al. (2009) Pluripotency can be rapidly and efficiently induced in human amniotic fluid-derived cells. Hum Mol Genet 18: $4340-4349$.

33. Zhao HX, Li Y, Jin HF, Xie L, Liu C, et al. (2010) Rapid and efficien reprogramming of human amnion-derived cells into pluripotency by three factors Oct4/Sox2/Nanog. Differentiation 80: 123-129.

34. Saito S, Yokoyama K, Tamagawa T, Ishiwata I (2005) Derivation and induction of the differentiation of animal ES cells as well as human pluripotent stem cells from fetal membrane. Human Cell 18: 135-141.

35. Ying QL, Nicols J, Chanbers I, Smith A (2003) BMP induction of Id proteins suppress differentiation and sustains embryonic stem cell self-renewal in collaboration with STAT3. Cell 115: 281-292.

36. Ying QL, Wray J, Nicols J, Batlle-Morea J, Doble B, et al. (2008) The ground state of embryonic stem cell self-renewal. Nature 453: 519-523.

37. Hanna JH, Saha K, Jaenisch R (2010) Pluripotency and cellular reprogramming: facts, hypotheses, unresolved issues. Cell 143: 508-525.

38. Daheron L, Opitz SL, Zaehres H, Lensch WM, Andrews PW, et al. (2004) LIF/ STAT3 signaling fails to maintain self-renewal of human embryonic stem cells. Stem Cells 22: $770-778$.

39. Xu RH, Chen X, Li DS, Li R, Addicks GC, et al. (2008) Nanog is a direct target of TGFß/Activin-mediated SMAD signaling in human ESCs. Cell Stem Cell 3 196-206.

40. Tamagawa T, Ishiwata I, Saito S (2004) Establishment and characterization of a pluripotent stem cell line derived from human amniotic membranes and induction of germ layers in vitro. Human Cell 17: 125-130. 
Citation: Saito S, Wang SW, Ku CC, Lin CLS, Wu DC, et al. (2011) Human Amnion-derived Pluripotent Stem Cells as a Promising Source for Regenerative Medicine and Tissue Engineering. J Bioengineer \& Biomedical Sci S2:005. doi:10.4172/2155-9538.S2-005

Page 7 of 7

41. Rao MS, Mattson MP (2001) Stem cells and aging: expanding and possibilities. Mech Ageing Dev 122: 713-734.

42. Stolzing A, Jones E, McGonagle D, Scott A (2008) Age-related changes in human bone marrow-derived mesenchymal stem cells: consequences for cell therapies. Mech Ageing Dev 129: 163-173.

43. Roobrouck VD, Ulloa-Montoya F, Verfaillie CM (2008) Self-renewal and differentiation capacity of young and aged stem cells. Exp Cell Res 314: 19371944.

44. Niwa $\mathrm{H}$ (2007) How is pluripotency determined and maintained? Development 134: 635-646.

45. Thomson M, Liu SJ, Zou LN, Smith Z, Meissner A, et al. (2011) Pluripotency factors in embryonic stem cells regulate differentiation into germ layers. Cell 145: $875-889$.
46. Huang YC, Lee IL, Tsai YF, Saito S, Lin YC, et al. (2010) Role of Jun dimerization protein 2(JDP2) in cellular senescence. Inflammation and Regeneration 30 507-519.

47. Akutsu H, Cowan CA, Melton D (2006) Human embryonic stem cells. Methods Enzymol 418: 78-92.

48. Rossant J (2008) Stem cells and early lineage development. Cell 132: 527-531.

49. Nicols J, Smith A (2009) Naïve and primed pluripotent states. Cell Stem Cell 4: 487-492.

50. Reubinoff BE, Pera MF, Fong CH, Trounson A, Bongso A (2000) Embryonic stem cell lines from human blastocysts: somatic differentiation in vitro. Nat Biotechnol 18: 399-404.

This article was originally published in a special issue, Regenerative Medicine handled by Editor(s). Dr. Lisa M Larkin, University of Michigan, USA. 